\title{
Calcium ion as cellular messenger
}

\author{
ZHENG Jie $^{1 *}$, ZENG XuHui $^{2 *} \&$ WANG ShiQiang ${ }^{3}$ \\ ${ }^{1}$ Department of Physiology and Membrane Biology, University of California, Davis, School of Medicine, Davis, CA 95616, USA; \\ ${ }^{2}$ Institute of Life Science, Nanchang University, Nanchang 330031, China; \\ ${ }^{3}$ College of Life Sciences, Peking University, Beijing 100871, China
}

Received December 10, 2014

Citation: Zheng J, Zeng XH, Wang SQ. Calcium ion as cellular messenger. Sci China Life Sci, 2015, 58: 1-5, doi: 10.1007/s11427-014-4795-y

The prominent role $\mathrm{Ca}^{2+}$ ion plays as a major small biological messenger is fascinating. There are many physiologically important ions, such as $\mathrm{Na}^{+}, \mathrm{K}^{+}, \mathrm{H}^{+}, \mathrm{Cl}^{-}, \mathrm{Ca}^{2+}, \mathrm{Mg}^{2+}$, $\mathrm{Fe}^{3+}$, and $\mathrm{PO}_{4}{ }^{3-}$ that participate in cell signaling. Among them, monovalent ions primarily contribute to rapid electrical signaling, while multivalent ions generally act as a co-factor for chemical reactions by associating with the host molecule through electrostatic or covalent interactions. $\mathrm{Ca}^{2+}$ plays both roles. Its transmembrane influx supports the plateau phase of cardiac action potential and helps set the speed of pacemaker potential. Inside the cell, $\mathrm{Ca}^{2+}$ switches on (or off) a large array of effectors that control crucial biological processes, such as exocytosis (including neurotransmitter release and secretion), muscle contraction, fertilization, enzymatic activities (e.g., the blood-clotting cascade), and immune responses to antigens [1].

Why is it $\mathrm{Ca}^{2+}$ instead of another ion, say, its earth metal ion cousin $\mathrm{Mg}^{2+}$, that has been favored through evolution to assume such a ubiquitous messenger role in biology? The answer-which likely lies in the unique match between the chemical properties of $\mathrm{Ca}^{2+}$ and the life on Earth-may not be straightforward or singular. It is interesting to observe that $\mathrm{Ca}^{2+}$ is predominantly coordinated in the interior of proteins by oxygen atoms [2]. In comparison, $\mathrm{Mg}^{2+}$ ions tend to be coordinated by phosphate groups of proteins and nucleotides (ATP, DNA, RNA), $\mathrm{Zn}^{2+}$ and $\mathrm{Cu}^{2+}$ by the sulfhydryl group of cysteine residues and by the imidazole group of histidine residues. Modern biological research has nonetheless revealed many facts that help explain how $\mathrm{Ca}^{2+}$ carries out its messenger function. In a simplified view, the cell effectively maintains the cytosolic $\mathrm{Ca}^{2+}$ concentration at extremely low levels $\left(\sim 100 \mathrm{nmol} \mathrm{L}^{-1}\right)$. (Keep in mind that calcium is the fifth most abundant element by mass in the human body, and that the concentration of extracellular $\mathrm{Ca}^{2+}$, which is separated by a thin lipid membrane from the cytosol, is $\sim 20,000$ fold higher. In comparison, $\mathrm{Mg}^{2+}$ exists in mmol L ${ }^{-1}$ concentrations on both sides of the plasma membrane.) When needed, the cytosolic $\mathrm{Ca}^{2+}$ concentration is transiently and locally increased by 10-to-100 fold. Effectors further strongly amplify this rapid chemical signal through cooperative binding of multiple $\mathrm{Ca}^{2+}$ ions. There is rich information now on mechanisms concerning cytosolic $\mathrm{Ca}^{2+}$ concentration control, $\mathrm{Ca}^{2+}$-effector interaction, and downstream effects.

\section{$1 \mathrm{Ca}^{2+}$ coordination chemistry and $\mathrm{Ca}^{2+}$ sensors} (Figure 1)

In solution, $\mathrm{Ca}^{2+}$ ion (as well as $\mathrm{Mg}^{2+}$ ion) is coordinated by six water molecules in an octahedral arrangement, with the electronegative $\mathrm{Ca}^{2+}$ ion interacting with the electron-donor oxygen atom. The hydration enthalpy for $\mathrm{Ca}^{2+}$ is quite high, at $-1577 \mathrm{kcal} \mathrm{mol}^{-11}$ ). It means that when $\mathrm{Ca}^{2+}$ transfers

*Corresponding author (email: jzheng@ucdavis.edu; xuhuizeng@ hotmail.com)

1) The hydration enthalpy for $\mathrm{Mg}^{2+}$ is higher than that of $\mathrm{Ca}^{2+}$ by more than $80 \mathrm{kcal} \mathrm{mol}^{-1}$, reflecting a much stronger interaction between $\mathrm{Mg}^{2+}$ and water. This is because $\mathrm{Mg}^{2+}$ exhibits greater electronegativity and hence exerts a greater pull on water or other ligands that are electron donors. This difference in strength of interaction with ligands was exploited in the design of divalent cation chelators such as EDTA (binds both $\mathrm{Ca}^{2+}$ and $\mathrm{Mg}^{2+}$ ) and EGTA (binds more specific $\mathrm{Ca}^{2+}$ ). Due to stronger interactions between $\mathrm{Mg}^{2+}$ and its ligands, $\mathrm{Mg}^{2+}$ ion blocks certain types of $\mathrm{Ca}^{2+}$ channels. In comparison, the hydration enthalpies for monovalent ions $\mathrm{K}^{+}, \mathrm{Na}^{+}$and $\mathrm{Cl}^{-}$are only $1 / 4$ to $1 / 5$ of that of $\mathrm{Ca}^{2+}$. 

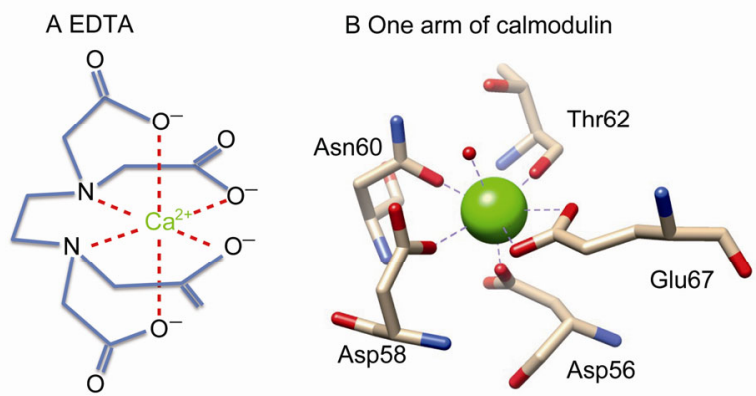

Figure $1 \mathrm{Ca}^{2+}$ coordination chemistry. A, A Ca ${ }^{2+}$ ion is coordinated by six ligands $(\mathrm{O}$ and $\mathrm{N})$ of EDTA. B, Key amino acids in one of the $\mathrm{Ca}^{2+}$-binding arms. $\mathrm{Ca}^{2+}$ is shown as a green sphere; the oxygen atom in a water molecule is shown as a small red sphere.

from the bulk solution to a protein the interactions with water need to be replaced by interactions with ligands of similar strengths. This requirement is illustrated by the $\mathrm{Ca}^{2+}$-EDTA complex, in which two amines and four carboxylates take the place of water molecules. Cooperativity among the ligands likely contributes to both specificity and affinity of this widely used divalent cation chelator. The same principal guides coordination of $\mathrm{Ca}^{2+}$ inside proteins.

To use $\mathrm{Ca}^{2+}$ as a cellular messenger, specific $\mathrm{Ca}^{2+}$ binding motifs have emerged in proteins through evolution. The well-known EF-hand is found in calmodulin, troponin $\mathrm{C}$, and a large number of other proteins. $\mathrm{Ca}^{2+}$ is coordinated by side-chain oxygen atoms of specific amino acids (Asp, Asn, Glu, Thr, and Ser), backbone carbonyl oxygen atoms, and sometimes oxygen atom of remaining water molecules. Noticeably the EF-hand motif often exists in multiple copies in the same protein where they are in close proximity to allow conformational coupling. Four EF-hand motifs are found in calmodulin and troponin $\mathrm{C}$. The $\mathrm{C} 2$ domain, found in protein kinase $\mathrm{C}$ and hundreds of other proteins, often coordinates two or three $\mathrm{Ca}^{2+}$ ions in close proximity. In the tetrameric voltage-gated $\mathrm{Ca}^{2+}$-regulated $\mathrm{BK}$ channel, each subunit contains two $\mathrm{Ca}^{2+}$-binding RCK domains; the eight RCK domains are tightly packed together to form a gating ring beneath the channel pore which exhibits $\mathrm{Ca}^{2+}$ dependent conformational rearrangement [3]. Similar to the case of cooperative binding of four oxygen molecules in hemoglobin, binding of multiple $\mathrm{Ca}^{2+}$ ions gives rise to strong cooperativity through allosteric coupling among the binding motifs. This results in an extraordinary boost in sensitivity to changes in cytosolic $\mathrm{Ca}^{2+}$ concentration.

While $\mathrm{Ca}^{2+}$ binding may directly alter the function of many host proteins, $\mathrm{Ca}^{2+}$ signaling is often carried out through dedicated $\mathrm{Ca}^{2+}$ sensors that are regulatory proteins. Calmodulin and troponin $\mathrm{C}$ are two examples of widely used $\mathrm{Ca}^{2+}$ sensors. Once activated by $\mathrm{Ca}^{2+}$, these sensors in turn modulate the function of various effectors. Multiple-step signaling is advantageous in enhancing sensitivity and flexibility. Calmodulin-mediated signaling is demonstrated nicely in this issue by an original study by Wang
HongBing and colleagues [4]. The study concerns calmodulin-mediated $\mathrm{Ca}^{2+}$ regulation of protein kinase IV (CaMKIV), which plays critical roles in the regulation of neuronal signaling and behavior. An increase in neuronal activity of cortical neurons is expected to cause an increase in cytosolic $\mathrm{Ca}^{2+}$ concentration, activating in turn calmodulin, CaMKIV, and the downstream targets of this kinase.

\section{$2 \mathrm{Ca}^{2+}$ homeostasis (Figure 2)}

The plasma $\mathrm{Ca}^{2+}$ concentration is tightly controlled and fluctuates only by $1 \%-2 \%$ of its normal level (low mmol $\mathrm{L}^{-1}$ ). A large fraction of $\mathrm{Ca}^{2+}$ ions bind to proteins (such as albumin) and anions (such as bicarbonate, citrate, phosphate and sulfate), while the remaining circulate in unbound form. To ensure a stable level of plasma $\mathrm{Ca}^{2+}$, there are readily available supplies. Intake of calcium from food is the main source for replenishing daily loss through urine and sweat. However, excess loss of plasma $\mathrm{Ca}^{2+}$ (hypocalcemia), e.g., due to heavy consumption of alcohol or tea, is balanced by dissolving calcium from bones and teeth, resulting in osteoporosis - spongy low-density bones. Parathyroid hormone released from parathyroid gland controls diet calcium intake, release of mineral calcium from bones by osteoclast and reabsorption of ionic calcium from urine in kidney. Calcium-sensing receptors (CaSRs) are responsible for detecting the extracellular (equivalent to the plasma) $\mathrm{Ca}^{2+}$ level in these organs, and control parathyroid hormone release and $\mathrm{Ca}^{2+}$ reabsorption. Genetic mutations in CaSRs lead to hypocalcemia or hypercalcemia. In this issue, Yang Jenny and colleagues [5] review the current understanding of how CaSRs detect extracellular $\mathrm{Ca}^{2+}$ level and contribute to calcium homeostasis.

While bones and teeth are the major mineral storage for plasma $\mathrm{Ca}^{2+}$, intracellular organelles such as endoplasmic reticulum (ER) and sarcoplasmic reticulum (SR) are the major $\mathrm{Ca}^{2+}$ stores for the cell. While the cytosolic $\mathrm{Ca}^{2+}$ concentration is maintained at the $100 \mathrm{nmol} \mathrm{L}^{-1}$ level, $\mathrm{Ca}^{2+}$ concentration in ER and SR can be 1,000- to 10,000-fold higher. Transient cytosolic $\mathrm{Ca}^{2+}$ spikes occur when $\mathrm{Ca}^{2+}$ is released from ER and SR into the cytosol. When the signal-

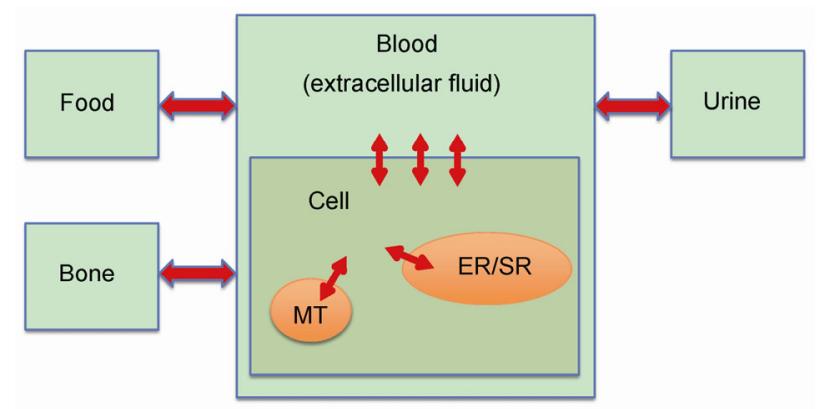

Figure 2 Major body compartments involved in the maintenance of $\mathrm{Ca}^{2+}$ equilibrium. 
ing mission is accomplished, $\mathrm{Ca}^{2+}$ is taken back into ER and SR for future use. Exchange between the extracellular and intracellular compartments also contributes to cytosolic $\mathrm{Ca}^{2+}$ dynamics, and often serves as the trigger for rapid $\mathrm{Ca}^{2+}$ release from intracellular stores. An extensive array of $\mathrm{Ca}^{2+}$ transport proteins are involved in these processes. Gaining structural and mechanistic understandings of these $\mathrm{Ca}^{2+}$ transport proteins has been a major focus of modern research on $\mathrm{Ca}^{2+}$ homeostasis and signaling.

\section{$3 \mathrm{Ca}^{2+}$ transport pathways (Figure 3)}

There are four major pathways for $\mathrm{Ca}^{2+}$ entrance across the plasma membrane. The pathway controlled by rapid electrical signaling (action potential) is mainly mediated by the voltage-gated $\mathrm{Ca}^{2+}\left(\mathrm{Ca}_{\mathrm{v}}\right)$ channels. There are a number of $\mathrm{Ca}_{\mathrm{v}}$ channels that vary in tissue and cell distribution, conductivity, and voltage sensitivity [6]. Auxiliary $\mathrm{Ca}_{v} \beta$ subunits are known to associate with the pore-forming $\mathrm{Ca}_{\mathrm{v}} \mathrm{\alpha}$ subunits to modify the flavor of channel properties. Further, a family of GTPase molecules called RGKs bind to $\mathrm{Ca}_{\mathrm{v}}$ channels and regulate their expression and biophysical properties. This is reviewed by Yang Jian and colleagues [6].

Chemical signals can also trigger $\mathrm{Ca}^{2+}$ influx at the plasma membrane. Receptors for chemical signals include nicotinic acetylcholine receptor (nAChR), ionotropic glutamate receptor, purinergic receptor, cyclic nucleotide-gated channels, etc. These are non-selective cation channels having various levels of $\mathrm{Ca}^{2+}$ permeability and selectivity. In many cases, the primary function of the receptor is to generate an excitatory current for electrical signaling. Nonetheless, $\mathrm{Ca}^{2+}$ influx through these channels does play important roles in regulating signal transduction and can inhibit channel activity through negative feedback.

Another group of $\mathrm{Ca}^{2+}$-permeable channels are the TRP channels. This is an extremely diverse collection of chan-

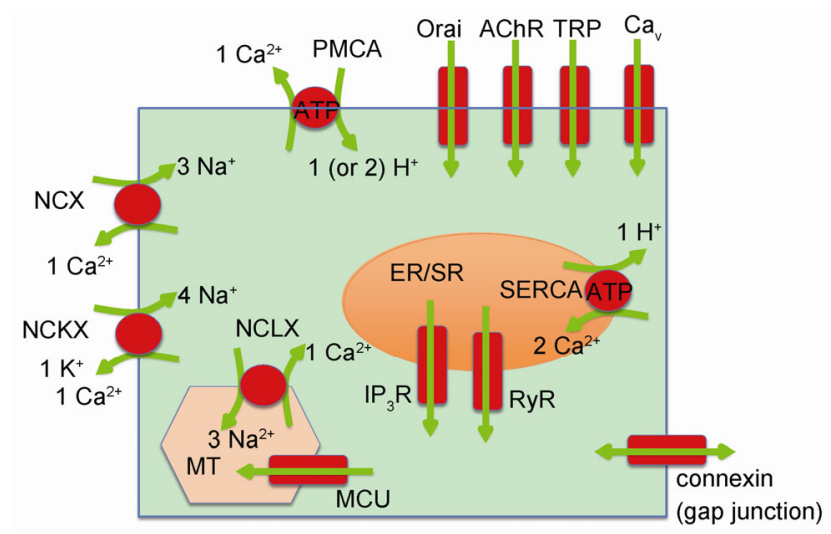

Figure 3 Examples of $\mathrm{Ca}^{2+}$ transporting membrane proteins. Arrows indicate the normal flux direction; numbers indicate the stoichiometry of coupled ion transport. nels that are responsive to a wide spectrum of physical and chemical stimuli. Many TRP channels are polymodal, meaning that they can be potently activated by multiple stimuli. Again, most TRP channels support electrical signaling but are $\mathrm{Ca}^{2+}$-permeable. The review on TRPC4 by Zhu Michael X. and colleagues [7] gives an example of the complicity of TRP channels.

Furthermore, the Orai $\mathrm{Ca}^{2+}$ channels are unique in that their activity is controlled by information coming from inside the cell. As discussed earlier, intracellular organelles ER and SR serve as cellular $\mathrm{Ca}^{2+}$ reservoirs. Exhaustion of these $\mathrm{Ca}^{2+}$ stores is sensed by an intracellular membrane protein called STIM (an EF-hand containing protein), which triggers aggregation and activation of Orai. This allows extracellular $\mathrm{Ca}^{2+}$ to enter the cytosol and replenish the store. This store-operated $\mathrm{Ca}^{2+}$ entry (SOCE) pathway and its role in cancer cells are reviewed by Pan Zui and Ma JianJie [8].

$\mathrm{Ca}^{2+}$ release from intracellular stores is mainly mediated by two types of ligand-gated channels, $\mathrm{IP}_{3}$ receptor $\left(\mathrm{IP}_{3} \mathrm{R}\right)$ and ryanodine receptor (RyR). The ligand for $\mathrm{IP}_{3} \mathrm{R}$, inositol 1,4,5-trisphosphate $\left(\mathrm{IP}_{3}\right)$, is a product of the phospholipase $\mathrm{C}$ (PLC) signaling pathway. Through the PLC pathway and $\mathrm{IP}_{3} \mathrm{R}$, chemical signals from the extracellular side regulate $\mathrm{Ca}^{2+}$ release from intracellular stores. While RyRs get their names from ryanodine, it is not an endogenous biological ligand. (Ryanodine is a poisonous alkaloid found in the plant Ryania speciosa and was used as a pesticide. It binds and closes RyRs at high concentrations but locks the channels in a half-open state at lower concentrations, leading to paralysis or massive muscle contraction, respectively.) The physiological ligand for RyR is $\mathrm{Ca}^{2+} \cdot \mathrm{Ca}^{2+}$ release due to activation of RyR is called $\mathrm{Ca}^{2+}$-induced $\mathrm{Ca}^{2+}$ release (CICR). In cardiomyocytes, CICR is triggered by $\mathrm{Ca}^{2+}$ influx across plasma membrane through $\mathrm{Ca}_{\mathrm{v}}$ channels. It provides the majority of $\mathrm{Ca}^{2+}$ ions that support contraction. Excessive $\mathrm{Ca}^{2+}$ release, however, causes arrhythmia. A review by Hector Valdivia and colleagues [9] illustrates how genetic mutations in a cardiomyocyte-specific RyR leads to arrhythmia.

$\mathrm{Ca}^{2+}$ ions entered into the cytosol through plasma and intracellular channels are taken back by transporters. Given the steep concentration gradients, $\mathrm{Ca}^{2+}$ reuptake by transporters is a challenging job. In the plasma membrane, there are one pump and two transporters to move $\mathrm{Ca}^{2+}$ out of the cell. The plasma membrane $\mathrm{Ca}^{2+}$-ATPase (PMCA) is a pump that uses the energy released from ATP hydrolysis to drive $\mathrm{Ca}^{2+}$ efflux. $\mathrm{Na}^{+}-\mathrm{Ca}^{2+}$ exchanger (NCX) relies on the transmembrane $\mathrm{Na}^{+}$concentration gradient as energy source, while $\mathrm{Na}^{+}-\mathrm{Ca}^{2+}-\mathrm{K}^{+}$exchanger (NCKX) takes advantage of both $\mathrm{Na}^{+}$and $\mathrm{K}^{+}$gradients. A major difference between PMCA and the exchangers is that PMCA exhibits high-affinity but low-capacity, while the exchangers exhibit low-affinity but high-capacity. Working together, the pump and exchangers ensure effective $\mathrm{Ca}^{2+}$ export. In the SR or ER membrane, sarcoendoplasmic reticulum $\mathrm{Ca}^{2+}$-ATPase 
(SERCA pump) serves a role similar to PMCA. Since the mitochondrial (MT) membrane is electrically charged (negative inside, close to $-200 \mathrm{mV}$ ), $\mathrm{Ca}^{2+}$ is driven into MT by the electrical potential through mitochondrial $\mathrm{Ca}^{2+}$ uniporter (MCU, a $\mathrm{Ca}^{2+}$-permeable channel). $\mathrm{Ca}^{2+}$ is extruded from MT by $\mathrm{H}^{+}-\mathrm{Ca}^{2+}$ exchanger (in non-excitable cells) or $\mathrm{Na}^{+}-\mathrm{Ca}^{2+}$ exchanger (NCLX); the latter is reviewed by Israel Sekler and colleagues [10].

\section{New frontiers for $\mathrm{Ca}^{2+}$ signaling research}

Due to buffering effects, $\mathrm{Ca}^{2+}$ ions are transiently trapped near the release site (channels and transporters). The rate of cytosolic $\mathrm{Ca}^{2+}$ diffusion could be further limited by geometric factors at many cellular structures such as cilia, neuronal dendrites, synaptic terminals. In many cases, $\mathrm{Ca}^{2+}$ sensors and $\mathrm{Ca}^{2+}$-dependent effectors are localized near the release site through protein-protein interactions. Localized $\mathrm{Ca}^{2+}$ signaling is beneficial for speed, specificity, as well as sensitivity. The ability to detect local events generated by a small number of $\mathrm{Ca}^{2+}$ ions and protein molecules has been greatly limited by the sensitivity and resolution of available methods. It is likely that the development of new $\mathrm{Ca}^{2+}$ sensors and super-resolution microscopy will substantially advance this area of research.

An exciting new area is the structural investigation of proteins involved in $\mathrm{Ca}^{2+}$ signaling, in particular the revealing of high-resolution structures of $\mathrm{Ca}^{2+}$ transport proteins. Crystallography continues to yield high-resolution structures of proteins packed in crystal lattice. Latest developments in cryo-electron microscopy (cryo-EM) technologies, especially for electron detection (e.g., the use of direct detection device K2), have demonstrated great promise for structural study of membrane proteins. Indeed, solving TRPV1 structures at resolutions up to $3.4 \AA$ by the cryo-EM approach [11] indicates that a new era of membrane protein structural investigation has arrived. In this issue, Wang LiGuo and Tonggu LiGe introduce the latest developments in preparation of membrane protein samples and lipid reconstitution methods for structural and functional studies [12].

Given the ubiquitous role of $\mathrm{Ca}^{2+}$ as a signaling ion, it is not surprising that so many diseases are caused by deregulation of $\mathrm{Ca}^{2+}$-mediated events. Knowledge on the role $\mathrm{Ca}^{2+}$ plays in hypertension, diabetes, excitotoxicity (apoptosis and necrosis), blood coagulation, neurodegenerative diseases, infertility, and others will continue to guide clinical practice and pharmaceutical pursuit. The advance in understanding the signaler will continue to signal new hope for patients.

1 Clapham DE. Calcium signaling. Cell, 2007, 131: 1047-1058

2 Katz AK, Glusker JP, Beebe SA, Bock CW. Calcium ion coordination: a comparison with that of beryllium, magnesium, and zinc. J Am Chem Soc, 1996, 118: 5752-5763

3 Yuan P, Leonetti MD, Hsiung Y, MacKinnon R. Open structure of the $\mathrm{Ca}^{2+}$ gating ring in the high-conductance $\mathrm{Ca}^{2+}$-activated $\mathrm{K}^{+}$channel. Nature, 2012, 481: 94-97

4 Song ZX, Chen Q, Ding Q, Zheng F, Li CW, Xu LP, Wang HB. Function of $\mathrm{Ca}^{2+}$-/calmodulin-dependent protein kinase IV in $\mathrm{Ca}^{2+}$-stimulated neuronal signaling and behavior. Sci China Life Sci, 2015, 58: 6-13

5 Zhang C, Miller CL, Brown EM, Yang JJ. The calcium sensing receptor: from calcium sensing to signaling. Sci China Life Sci, 2015, 58: 14-27

6 Buraei Z, Lumen E, Kaur S, Yang J. RGK regulation of voltage-gated calcium channels. Sci China Life Sci, 2015, 58: 28-38

7 Fu J, Gao ZB, Shen B, Zhu MX. Canonical transient receptor potential 4 and its small molecule modulators. Sci China Life Sci, 2015, 58: 39-47

8 Pan Z, Ma JJ. Open Sesame: treasure in store operated calcium entry pathway for cancer therapy. Sci China Life Sci, 2015, 58: 48-53

9 Zhao YT, Valdivia CR, Gurrola GB, Hernández JJ, Valdivia HH. Arrhythmogenic mechanisms in ryanodine receptor channelopathies. Sci China Life Sci, 2015, 58: 54-58

10 Nita LI, Hershfinkel M, Sekler I. Life after the birth of the mitochondrial $\mathrm{Na}^{+} / \mathrm{Ca}^{2+}$ exchanger, NCLX. Sci China Life Sci, 2015, 58: 59-65

11 Liao M, Cao E, Julius D, Cheng Y. Structure of the trpv1 ion channel determined by electron cryo-microscopy. Nature, 2013, 504: 107-112

12 Wang LG, Tonggu LG. Membrane protein reconstitution for functional and structural studies. Sci China Life Sci, 2015, 58: 66-74

Open Access This article is distributed under the terms of the Creative Commons Attribution License which permits any use, distribution, and reproduction in any medium, provided the original author(s) and source are credited. 


\section{Biographical Sketch}

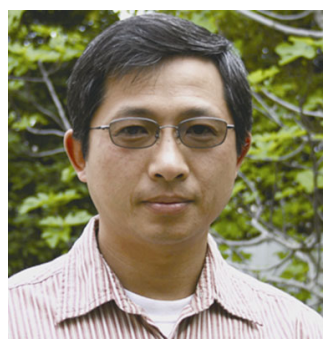

Dr. Zheng Jie is a Professor in School of Medicine at the University of California at Davis, USA, where he serves as a faculty member in the Department of Physiology and Membrane Biology since 2004. He earned his bachelor's degree in physiology and biophysics in 1988, and a master's degree in biophysics in 1991 from Peking University, Beijing, China. He earned his Ph.D. in physiology in 1998 from Yale, where he studied with Dr. Fredrick J. Sigworth on patch-clamp recording, single-channel analysis, and voltage-dependent channel activation mechanism. He received his postdoctoral training at Howard Hughes Medical Institute and the University of Washington during 1999-2003, working with Dr. William N. Zagotta on the cyclic nucleotide-gated channels activation mechanism and novel ion channel fluorescence techniques. Currently, his research focuses on the activation mechanism of the temperature-sensitive TRP channels.

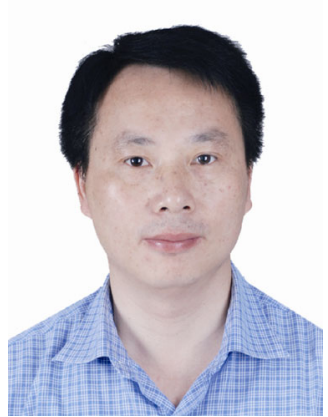

Dr. Zeng XuHui is a "Jing-Gang Scholar" Professor in Nanchang University and a selected winner of the "Gan-Po 555 Excellence Project" in Jiangxi Province. He finished his postdoctoral training in Washington University in St. Louis, School of Medicine, and served as a Research Instructor there before joining the Institute of Life Science in Nanchang University in 2011. Dr. Zeng has devoted his research efforts on understanding the general biophysical properties of ion channels together with the underlying mechanisms by which the ion channels would be regulated. At present, Dr. Zeng focuses on investigating the components, the physiological functions and the clinical relevance of ion channels in matured mammalian sperm. Dr. Zeng has contributed significantly to a series of research work published on prestigious peer-reviewed journals, such as Nature, Nature Structural Biology, Proceedings of the National Academy of Sciences, Journal of Neuroscience, Journal of General Physiology. Dr. Zeng is currently responsible for several research projects financially supported by the National Natural Science Foundation or Ministry of Science and Technology of China. 